\title{
Impact of Helmet Use in Traumatic Brain Injuries Associated with Recreational Vehicles
}

\author{
Latha Ganti, ${ }^{1,2,3,4}$ Aakash N. Bodhit, ${ }^{1,2}$ Yasamin Daneshvar, ${ }^{1,2}$ Pratik Shashikant Patel, ${ }^{1,2}$ \\ Christa Pulvino, ${ }^{1}$ Kelsey Hatchitt, ${ }^{1}$ Robyn M. Hoelle, ${ }^{2}$ Keith R. Peters, ${ }^{1,3,5}$ \\ Sudeep Kuchibhotla, ${ }^{1}$ Lawrence Lottenberg, ${ }^{1,6}$ Andrea Gabrielli, ${ }^{6}$ Anna Mazzuoccolo, ${ }^{1,2}$ \\ Marie-Carmelle Elie-Turenne, ${ }^{2}$ Tricia Falgiani, ${ }^{1,2}$ Porter W. Maerz, ${ }^{1}$ Shivam M. Kharod, ${ }^{1}$ \\ Lauren M. Conroy, ${ }^{1}$ Hussain M. Khalid, ${ }^{1}$ and J. Adrian Tyndall ${ }^{2}$
}

${ }^{1}$ Center for Brain Injury Research and Education, University of Florida College of Medicine, 1329 SW 16th Street, Suite 4270, Gainesville, FL 32610, USA

${ }^{2}$ Department of Emergency Medicine, University of Florida College of Medicine, Gainesville, FL 32610, USA

${ }^{3}$ Department of Neurological Surgery, University of Florida College of Medicine, Gainesville, FL 32610, USA

${ }^{4}$ Division of Clinical Research, Emergency Medicine \& Neurological Surgery, Toral Family Foundation, Davie, FL 33325, USA

${ }^{5}$ Department of Radiology, University of Florida College of Medicine, Gainesville, FL 32610, USA

${ }^{6}$ Department of Anesthesiology, University of Florida College of Medicine, Gainesville, FL 32610, USA

Correspondence should be addressed to Latha Ganti; lathagantimd@gmail.com

Received 25 June 2013; Revised 13 August 2013; Accepted 14 August 2013

Academic Editor: John Iskander

Copyright (C) 2013 Latha Ganti et al. This is an open access article distributed under the Creative Commons Attribution License, which permits unrestricted use, distribution, and reproduction in any medium, provided the original work is properly cited.

\begin{abstract}
Objective. To study the impact of helmet use on outcomes after recreational vehicle accidents. Methods. This is an observational cohort of adult and pediatric patients who sustained a TBI while riding a recreational vehicle. Recreational vehicles included bicycles, motorcycles, and all-terrain vehicles (ATVs), as well as a category for other vehicles such as skateboards and scooters. Results. Lack of helmet use was significantly associated with having a more severe traumatic brain injury and being admitted to the hospital. Similarly, $25 \%$ of those who did wearing a helmet were admitted to the ICU versus $36 \%$ of those who did not $(P=0.0489)$. The hospital length of stay was significantly greater for patients who did not use helmets. Conclusion. Lack of helmet use is significantly correlated with abnormal neuroimaging and admission to the hospital and ICU; these data support a call for action to implement more widespread injury prevention and helmet safety education and advocacy.
\end{abstract}

\section{Introduction}

In recent years, the use of recreational vehicles (RVs), such as on- and off-road motorcycles and all-terrain vehicles (ATVs), has increased significantly in popularity. Nearly one in five Americans (19.2\%) aged sixteen and older participated one or more times in off-highway recreation within the past year. The use of these vehicles is especially popular in the under-thirty age group [1]. Unfortunately, RV use puts a person at risk of sustaining a traumatic brain injury (TBI), which is a leading cause of injury-related death and disability in the US [2]. Incidence of these injuries as a result of RV use may be on the rise. While the overall rate of motor vehicle-related TBI deaths decreased between 1993 and 2007, the rate of motorcycle-related TBI deaths actually increased significantly during those years [2]. In fact, although motorcycles account for only $2 \%$ of vehicle registrations in the US, motorcycle accidents are responsible for $10 \%$ of traffic-related deaths [3]. Bicycle riding is also a common activity particularly among children. In USA, approximately $70 \%$ of children aged from 5 to 14 ride bicycles. Head and brain injuries during a crash are the worst danger associated with bicycle riding. According to the US Centers for Disease Control, head injury is the most common cause of death and serious disability from bicycle crashes. 
In addition to being a leading cause of death, TBIs can dramatically diminish quality of life for patients who survive. In one study, employment rate prior to sustaining a moderate or severe TBI was $80 \%$; at three months after injury, employment rate was $15 \%$, and at 3 years after injury, employment rate had only increased to 55\% [4]. Furthermore, the high incidence of TBIs in the US presents a major public health problem since patients with these injuries often end up seeking medical care later, sometimes long after the injury, with complaints of ongoing symptoms [5].

Therefore, preventative measures must be implemented to reverse the trend of recreational vehicle-related TBIs. The first step is to document the burden of the problem. In this study we sought to study the impact of helmet use on the clinical outcomes after head injury.

\section{Methods}

This IRB approved study is an observational cohort of adult and pediatric patients who presented to the emergency department following a TBI while riding a recreational vehicle during a 30-month period from January 2008 to August 2010. Full methodological details have been previously reported [6]. Briefly, cohort identification was accomplished using the following ICD-9 codes: 800.0-801.9, 803.0-804.9, 850.0-854.1, 995.55, 959.01, and 950.1-950.3. The injury e code matrix was used to classify vehicles as "onroad" or "off-road" [7]. The study was conducted at a level-1 trauma center located in a college town of 50,000 students with a 13-county catchment area in the North Central Florida region where the recreational use of off-road vehicles is particularly high. Recreational vehicles included bicycles, motorcycles, and all-terrain vehicles (ATVs), as well as a category for other vehicles such as skateboards and scooters. Data were collected for 482 patients. It was a subset of a cohort that included all traumatic brain injury patients regardless of their mechanism of injury. Data included demographic information (age, gender, race, etc.); prehospital care data when available (prehospital GCS score); and information about their injury (mechanism of injury, signs and symptoms associated with injury). Signs, and symptoms included loss of consciousness (LOC), alteration of consciousness (AOC), posttraumatic amnesia (PTA), any episode of vomiting after injury, and any reported seizure activity after injury. Outcome variables included ED admission TBI severity, clinical data, head CT findings, need for hospital admission, and ICU admission. Data were also collected for 72-hour return to ED and 30-day hospital readmission.

Data were entered into research electronic data capture (REDCap), which is a secure, web-based application hosted by our institution's center for translational science institute (CTSI) and is designed to support traditional clinical data capture. Statistical analyses were performed in JMP 9.0 (SAS institute, Cary, NC, USA) for the Macintosh.

\section{Results}

The cohort of 478 was $75 \%$ males. The median age was 25 years (IQR 17-44, range 2-85). There were 143 (30\%)
TABLE 1: Classification of vehicles as on- or off-road, per injury e code matrix.

\begin{tabular}{lcc}
\hline Type of vehicle/animal (other) & On-road & Off-road \\
\hline Scooter $(n=28)$ & 22 & 6 \\
Skateboard $(n=18)$ & 0 & 18 \\
Golf cart $(n=11)$ & 0 & 11 \\
Horse $(n=10)$ & 0 & 10 \\
Bicycle $(n=143)$ & 93 & 50 \\
Motorcycle $(n=167)$ & 127 & 40 \\
ATV $(n=91)$ & 3 & 88 \\
\hline
\end{tabular}

TABLE 2: Types of vehicles, transfer status, and deaths.

\begin{tabular}{lccc}
\hline Type of vehicle & Transfer & No transfer & Deaths \\
\hline Bicycle $(n=143)$ & 18 & 125 & $5(1,4)$ \\
Motorcycle $(n=167)$ & 21 & 146 & $15(1,14)$ \\
ATV $(n=91)$ & 20 & 71 & $1(1,0)$ \\
Other $(n=67)$ & 7 & 60 & $2(0,2)$ \\
Watercraft $(n=10)$ & 4 & 6 & 0 \\
\hline Total $(n=478)$ & 70 & 408 & $23(3,20)$ \\
\hline
\end{tabular}

TABLE 3: Types of vehicles and presenting GCS.

\begin{tabular}{lcccc}
\hline Type of vehicle & GCS 13-15 & GCS 9-12 & GCS 3-8 & Deaths \\
\hline Bicycle $(n=143)$ & $132(92.3 \%)$ & $2(1.4 \%)$ & $9(6.3 \%)$ & $5(3.5 \%)$ \\
Motorcycle $(n=167)$ & $111(66.5 \%)$ & $8(4.8 \%)$ & $48(28.7 \%)$ & $15(9 \%)$ \\
ATV $(n=91)$ & $69(75.8 \%)$ & $1(1.1 \%)$ & $21(23.1 \%)$ & $1(1.1 \%)$ \\
Other $(n=67)$ & $58(86.6 \%)$ & $4(6 \%)$ & $5(7.4 \%)$ & $2(3 \%)$ \\
Scooter $(n=28)$ & $23(82.1 \%)$ & $2(7.2 \%)$ & $3(10.7 \%)$ & $2(7.1 \%)$ \\
Skateboard $(n=18)$ & $18(100 \%)$ & 0 & 0 & 0 \\
Golf cart $(n=11)$ & $9(81.8 \%)$ & $2(18.2 \%)$ & 0 & 0 \\
Horse $(n=10)$ & $8(80 \%)$ & 0 & $2(20 \%)$ & 0 \\
Watercraft $(n=10)$ & $10(100 \%)$ & 0 & 0 & 0 \\
\hline \multicolumn{5}{c}{ Patients excluding transferred } \\
Bicycle $(n=125)$ & $116(92.8 \%)$ & 0 & $9(7.2 \%)$ & $4(3.2 \%)$ \\
Motorcycle $(n=146)$ & $98(67.1 \%)$ & $7(4.8 \%)$ & $41(28.1 \%)$ & $14(9.6 \%)$ \\
ATV $(n=71)$ & $54(76.1 \%)$ & $1(1.4 \%)$ & $16(22.5 \%)$ & 0 \\
Other $(n=60)$ & $52(86.7 \%)$ & $3(5 \%)$ & $5(8.3 \%)$ & $2(3 \%)$ \\
Scooter $(n=28)$ & $23(82.1 \%)$ & $2(7.2 \%)$ & $3(10.7 \%)$ & $2(7.1 \%)$ \\
Skateboard $(n=16)$ & $16(100 \%)$ & 0 & 0 & 0 \\
Golf cart $(n=8)$ & $7(87.5 \%)$ & $1(12.5 \%)$ & 0 & 0 \\
Horse $(n=8)$ & $6(75 \%)$ & 0 & $2(25 \%)$ & 0 \\
Watercraft $(n=6)$ & $6(100 \%)$ & 0 & 0 & 0 \\
\hline
\end{tabular}

bicycle riders, 168 (35\%) motorcycle riders, and 91 (19\%) ATV riders, and $66(14 \%)$ were on skateboards, scooters, or other recreational vehicles; $10(2 \%)$ were involved in watercraft accidents (Table 1). Tables 2 and 3 summarize the numbers of patients who came in as transfers versus directly from the scene, with the corresponding number of deaths in each category. Table 3 further breaks down this information by TBI severity and again delineates the number of deaths. Table 4 provides age ranges for each vehicles type. 
TABLE 4: Vehicle type by age range.

\begin{tabular}{lccccccccc}
\hline & $0-4 \mathrm{y}$ & $5-14 \mathrm{y}$ & $15-19 \mathrm{y}$ & $20-24 \mathrm{y}$ & $25-34 \mathrm{y}$ & $35-44 \mathrm{y}$ & $45-54 \mathrm{y}$ & $55-64 \mathrm{y}$ & $\geq 65 \mathrm{y}$ \\
\hline Whole cohort $(n=478)$ & $10(2.1 \%)$ & $80(16.7 \%)$ & $75(15.7 \%)$ & $70(14.6 \%)$ & $71(14.9 \%)$ & $53(11.1 \%)$ & $65(13.6 \%)$ & $38(8 \%)$ & $16(3.3 \%)$ \\
Bicycle $(n=143)$ & $4(2.8 \%)$ & $20(14 \%)$ & $16(11.2 \%)$ & $27(18.9 \%)$ & $20(14 \%)$ & $14(9.8 \%)$ & $21(14.7 \%)$ & $16(11.2 \%)$ & $5(3.5 \%)$ \\
Motorcycle $(n=167)$ & 0 & $16(9.6 \%)$ & $22(13.2 \%)$ & $21(12.5 \%)$ & $25(15 \%)$ & $28(16.7 \%)$ & $30(18 \%)$ & $17(10.2 \%)$ & $8(4.8 \%)$ \\
ATV $(n=91)$ & $4(4.4 \%)$ & $28(30.7 \%)$ & $18(19.8 \%)$ & $7(7.7 \%)$ & $18(19.8 \%)$ & $7(7.7 \%)$ & $6(6.6 \%)$ & $1(1.1 \%)$ & $2(2.2 \%)$ \\
Other $(n=67)$ & $2(3 \%)$ & $15(22.4 \%)$ & $15(22.4 \%)$ & $13(19.4 \%)$ & $7(10.4 \%)$ & $3(4.5 \%)$ & $7(10.4 \%)$ & $4(6 \%)$ & $1(1.5 \%)$ \\
Scooter $(n=28)$ & $2(7.1 \%)$ & $5(17.9 \%)$ & $3(10.7 \%)$ & $9(32.1 \%)$ & $2(7.1 \%)$ & $1(3.6 \%)$ & $4(14.3 \%)$ & $2(7.2 \%)$ & 0 \\
Skateboard $(n=16)$ & 0 & $5(27.8 \%)$ & $9(50 \%)$ & $4(22.2 \%)$ & 0 & 0 & 0 & 0 & 0 \\
Golf cart $(n=8)$ & 0 & $2(18.2 \%)$ & $2(18.2 \%)$ & 0 & $4(36.3 \%)$ & $1(9.1 \%)$ & $1(9.1 \%)$ & 0 & $1(9.1 \%)$ \\
$\quad$ Horse $(n=8)$ & 0 & $3(30 \%)$ & $1(10 \%)$ & 0 & $1(10 \%)$ & $1(10 \%)$ & $1(10 \%)$ & $2(20 \%)$ & 0 \\
Watercraft $(n=10)$ & 0 & $1(10 \%)$ & $4(40 \%)$ & $2(20 \%)$ & $1(10 \%)$ & $1(10 \%)$ & $1(10 \%)$ & 0 & 0 \\
\hline
\end{tabular}

TABLE 5: Characteristics of riders of different recreational vehicles.

\begin{tabular}{lccc}
\hline & + helmet & $\begin{array}{c}\% \text { males riding } \\
\text { recreational } \\
\text { vehicles }\end{array}$ & $\begin{array}{c}\text { Median age } \\
\text { (IQR; range) }\end{array}$ \\
\hline $\begin{array}{l}\text { Bicycle }(n=143) \\
\text { Motorcycle } \\
(n=168)\end{array}$ & $29(20 \%)$ & 73 & $26(19-48 ; 3-85)$ \\
$\begin{array}{l}\text { ATV }(n=91) \\
\text { Other }(\text { skateboard, }\end{array}$ & $13(14 \%)$ & 70 & $18(13-32 ; 2-72)$ \\
scooter $)(n=54)^{*}$ & $9(14 \%)$ & 70 & $19(14-28 ; 4-58)$ \\
\hline
\end{tabular}

* 12 patients were excluded as they were injured while using vehicles where normally the riders do not wear helmets such as a golf cart. Also watercraft injuries are not included in the table.

TABLE 6: TBI severity and symptoms at injury based on helmet use.

\begin{tabular}{lcc}
\hline & $\begin{array}{c}+ \text { helmet } \\
(N=128)\end{array}$ & $\begin{array}{c}\text { No helmet } \\
(N=328)\end{array}$ \\
\hline Mild (GCS 13-15) & $105(82 \%)$ & $255(77.7 \%)$ \\
Moderate (GCS 9-12) & $2(1.5 \%)$ & $11(3.3 \%)$ \\
Severe (GCS 3-8) & $21(16.4 \%)$ & $62(18.9 \%)$ \\
\hline
\end{tabular}

Helmet use ranged from 14 to $46 \%$ in different vehicle types (Table 5). Helmet was use was a significant predictor of TBI severity, when controlling for vehicle type and gender of patient. For analytical purpose, we combined patients with GCS scores of 3-8 and 9-12 in one group, as we had few patients with GCS score of 9-12. Helmet use was associated with less severe TBI $(\mathrm{OR}=2.1,95 \% \mathrm{CI}=1.19-3.81)$. TBI severity was significantly worse in both the prehospital $(P=0.015)$ and $\mathrm{ED}(P=0.012)$ environments when a helmet was not worn (Table 6). Helmet use was associated with significantly less likelihood of having an abnormal CT $(P=0.0085, \mathrm{OR}=0.56, \mathrm{CI}=0.36-0.86)$. Of the CT abnormalities (Table 7), 92\% were bleeds and $61.5 \%$ were fractures. Any abnormal bleeding (included epidural, subdural, subarachnoid, intraparenchymal, and any contusion) on head CT scan was more significantly more common in nonhelmeted patients compared to helmeted patients $(P=$ $0.043, \mathrm{OR}=1.58, \mathrm{CI}=1.01-2.48)$. This remains true for the finding of fracture (skull fracture including calvarial fractures
TABLE 7: CT abnormalities by helmet use.

\begin{tabular}{lccc}
\hline CT abnormality $(n=420)$ & $\begin{array}{c}\text { Helmeted } \\
(n=121)\end{array}$ & $\begin{array}{c}\text { Nonhelmeted } \\
(n=299)\end{array}$ & $P$ value \\
\hline \multicolumn{4}{c}{ Cranial and intracranial } \\
$\begin{array}{l}\text { Fracture of skull } \\
\begin{array}{l}\text { Calvarial fracture through } \\
\text { carotid canal/foramen } \\
\text { magnum }\end{array}\end{array}$ & 0 & $8(2.71)$ & - \\
$\begin{array}{l}\text { Epidural, subdural, and } \\
\text { subarachnoid hemorrhages }\end{array}$ & $39(32.2 \%)$ & $133(44.5 \%)$ & 0.02 \\
$\begin{array}{l}\text { Intraparenchymal hemorrhage } \\
\text { including intraventricular }\end{array}$ & $22(18.2 \%)$ & $90(30.1 \%)$ & 0.004 \\
$\begin{array}{l}\text { hemorrhage and contusions } \\
\text { Diffuse axonal injury }\end{array}$ & $9(7.4 \%)$ & $13(4.3 \%)$ & $\mathrm{NS}$ \\
\hline \multicolumn{4}{c}{ Extracranial } \\
$\begin{array}{l}\text { Fractures of maxillo-facial } \\
\text { bones }\end{array}$ & $14(11.6 \%)$ & $61(20.4 \%)$ & 0.033 \\
$\begin{array}{l}\text { Extracalvarial soft tissue } \\
\text { swelling/defect }\end{array}$ & $7(5.8 \%)$ & $66(22 \%)$ & $<0.0001$ \\
\hline
\end{tabular}

through carotid canal and foramen magnum) on head CT scan $(P=0.0005, \mathrm{OR}=2.53, \mathrm{CI}=1.48-4.33)$. Overall, $11 \%$ required neurosurgical intervention (ventriculostomy or craniotomy) for their injury.

Lack of helmet use was associated with higher hospital admission rate (59.5\% versus $50.7 \%)$, but it was not statistically significant. Similarly, $25 \%$ of those wearing a helmet were admitted to the ICU, whereas this number rose to $35 \%$ for those not wearing a helmet $(P=0.04)$. The maximum length of stay in the hospital was significantly greater for patients who did not use helmets (144 days versus 46 days for helmet users). Thirty-day readmission rate was also higher for nonhelmeted patients (6\%) than for helmeted patients (2\%).

Alcohol use before injury was significantly higher among those not wearing a helmet compared to those who did (23\% versus $2 \%, P<0.0001)$. Also, $66.7 \%$ of those without helmet had a positive drug screen ( 28 out of 42 screened) compared to $50 \%$ (9 out of 18) for those with helmets. Urine drug screening can detect cannabinoid, amphetamines, cocaine, barbiturates, and phencyclidine. 
TABLE 8: Injury characteristics.

\begin{tabular}{lccc}
\hline & $\begin{array}{c}\text { + helmet } \\
(N=128)\end{array}$ & $\begin{array}{c}\text { No helmet } \\
(N=328)\end{array}$ & $\begin{array}{c}\text { Not } \\
\text { applicable } \\
(N=22)\end{array}$ \\
\hline $\begin{array}{l}\text { Associated } \\
\text { vomiting }\end{array}$ & $12(9.4 \%)$ & $28(8.7 \%)$ & \\
Associated seizure & $7(5.5 \%)$ & $14(3 \%)$ & \\
LOC & $98(76 \%)$ & $220(67 \%)$ & $15(68.1 \%)$ \\
LOC $>30$ & $16(16.5 \%)$ & $39(18.5 \%)$ & \\
AOC & $82(64 \%)$ & $210(64 \%)$ & $12(54.5 \%)$ \\
PTA & $55(43 \%)$ & 136 & $8(36.4 \%)$ \\
\hline
\end{tabular}

LOC: loss of consciousness; AOC: alteration in consciousness; PTA: posttraumatic amnesia.

Injury clinical presentations by helmet use are summarized in Table 8 . There were not any statistically significant differences in signs and symptoms after TBI in patients wearing helmet compared to those without helmets.

\section{Discussion}

These data demonstrate that lack of helmet use is significantly correlated with abnormal head CT scans, admission to the ICU, and worse TBI severity. Also, helmet use is associated with less hospital admission rate. This relationship between helmet use and TBI severity has been supported by other studies done to show the preventive ability of helmets against the effects of impact on human skull models. Studies have shown that bicycle helmet use reduces the risk of brain injury by $88 \%$ [8]. A recent study that conducted crush tests using human cadaver skulls demonstrated that wearing a helmet can reduce the acceleration experienced by up to $87 \%$ during impact and also help the skull in resisting forces up to 47 pounds [9]. Population-based studies conducted to find out effectiveness of helmets in reducing severity of head injuries have reported results similar to those found in our study. In a review of the literature regarding motorcycle helmet use, "the authors found voluminous support for motorcycle helmet use as a way to prevent severe TBI and traffic fatalities" [3]. In a review conducted by Thompson et al., the authors reported that helmets reduce bicycle-related head and face injuries in bicyclists of all ages regardless of crash type [10]. A recent case-control study conducted in Canada reported a significant increase in mortality associated with nonhelmet use in bicyclists compared to helmet use [11]. Similarly, the effectiveness of helmet use in reducing risk of head injury and mortality in motorcycle riders is well documented [12, 13]. Preventive effects of helmets were also reported in moped or scooter riders in a study published by Hooten and Murad [14]. A West Virginia study [15] found that nonhelmeted riders were significantly more likely to be admitted to the hospital and sustain more injuries. A similar epidemiological review of pediatric ATV riders in Tennessee [16] notes that helmet use resulted in fewer injuries to the head, neck, and face. These findings demonstrate the benefit of wearing helmets during recreational vehicle use and suggest a call for action to implement more widespread injury prevention and helmet safety education and advocacy.

Implementation of universal laws for helmet use has been a controversial issue. The arguments against the universal helmet use laws are reduction of freedom, perceived inconvenience to use helmets, and even more chances of cervical injuries in helmet users after certain speed due to mechanism involved $[17,18]$. The concerns about increased chances of cervical spine injuries in helmet users have been addressed in other studies, and it has been reported that helmet use does not increase chances of cervical spine injuries $[19,20]$, but in fact it can reduce such injuries [21]. In an Italian study conducted to compare the impact of compulsory helmet use, it was found that, after adoption of law, there was significant decrease in neurosurgical hospital admissions for motorcycle- or moped-related TBI. This decrease in TBIs was evident in all age groups. One significant finding was that epidural hematomas were rare after the adoption of law, which was enforced strictly by police [22]. Currently, only 20 states and District of Columbia have helmet laws that apply to each age group. A study that used the crosssectional time series data from National Highway Traffic Safety Administration (NHTSA) for a period of 1975-2004 demonstrated that states with universal helmet laws have approximately $22-33 \%$ lower fatality rates for motorcycle users compared to states without universal helmet laws. Same study found that partial coverage helmet laws also reduce fatality in motorcycle riders by about $7-10 \%$ [23]. Dao et al. reported that hospital admitted patients in states with mandatory helmet laws have decreased rate of cervical spine injuries compared to those in states with flexible helmet laws [24]. A statewide hunter education program in Arkansas for ATV safety has been reported to be successful in a surveybased study [25].

Along with establishment and strict implementation of universal helmet laws, health education programs focused on children, adolescents, and young adults will most likely improve the helmet use rates. A large number of children, adolescents, and young adults use recreational vehicles, and a lot of them are inexperienced and are less likely to follow traffic rules [17]. Community participation should be an integral part of such programs as it improves effectiveness and success rates of such programs. Community-based and collaborative approach is necessary for such programs to succeed, as only education can increase the safety knowledge in targeted population, but not necessarily the safe behavior by targeted population [26].

Study limitations included the following. Our data were significant in an aspect that they included all recreational vehicle types; however, the actual type and quality, proper fitting, and mechanics of the helmets were not studied. Furthermore, no significant details on the kinetics of the impact were available, such as speed and angle of impact and body mass of subjects. Indeed, one study on hockey helmets found that the current methods of safety testing may miss some important risks, and additional testing conditions should be added to existing test protocols [27]. Therefore, the best way to decrease the occurrence of RV-related TBIs is 
to provide public education about the relationship between these injuries, recreational vehicles, and helmet use while simultaneously conducting research to design more effective helmets and enforce their safety standard. Also, there were relatively few moderate TBIs in our cohort. The reason for this may be that a significant percentage of TBIs that are initially moderate go on to become severe very quickly, either because of intrinsic injury/pathology or because of how GCS gets reported.

\section{Conclusion}

These data demonstrate that lack of helmet use is significantly correlated with abnormal head CT scans (fractures), admission to the hospital, admission to the ICU, and overall worse TBI severity both in the prehospital and ED environments. These results underscore the importance of wearing helmets during recreational vehicle use and suggest a similar benefit for all recreational activity at high risk of brain impact. We join others in supporting a call for action to implement more widespread injury prevention and helmet safety education and advocacy.

\section{What Is Already Known on This Subject}

(i) Helmet use is a good preventative measure against head injury.

(ii) Many states have helmet laws, especially for children; unfortunately not all states do.

\section{What This Study Adds}

(i) Lack of helmet use is significantly correlated with numerous concrete outcome measures including neurological deficits, radiological signs of skull fracture, and admission to the hospital and ICU.

(ii) Overall, not wearing a helmet resulted in worse TBI severity both in the prehospital and ED environments.

(iii) Presenting these updated statistics is important especially in light of the rise in recreational vehicle use.

\section{Conflict of Interests}

The authors declare that they have no conflict of interests.

\section{Authors' Contribution}

Latha Ganti, Aakash N. Bodhit, Pratik Shashikant Patel, and Yasamin Daneshvar conducted the study. Latha Ganti, Aakash N. Bodhit, Pratik Shashikant Patel, Yasamin Daneshvar, Anna Mazzuoccolo, Shivam M. Kharod, Christa Pulvino, and Kelsey Hatchitt collected the data. Aakash N. Bodhit, Pratik Shashikant Patel, Yasamin Daneshvar, and Latha Ganti performed the statistical analyses, and Aakash N. Bodhit, Pratik Shashikant Patel, and Yasamin Daneshvar crosschecked the data. Latha Ganti and Keith R. Peters supervised the conduct of the research and data collection. Latha Ganti, Christa Pulvino, Robyn M. Hoelle, and Aakash N. Bodhit drafted the paper, and all authors contributed substantially to its revision. All authors read and approved the final paper.

\section{Acknowledgments}

This work is supported by grant funding from (1) the Toral Family Foundation, Davie, FL, USA and (2) the NIH/NCRR Clinical and Translational Science Award to the University of Florida UL1 RR029890.

\section{References}

[1] H. Cordell, C. Betz, G. Green, and B. Stephens, "Offhighway vehicle recreation in the United States and its regions and states: a national report from the National Survey on Recreation and the Environment (NSRE)," pp. 8-12, 2008, http://www.fs.fed.us/recreation/programs/ohv/IrisReclrpt.pdf.

[2] V. G. Coronado, L. Xu, S. V. Basavaraju et al., "Surveillance for traumatic brain injury-related deaths-United States, 19972007," Morbidity and Mortality Weekly Report, vol. 60, no. 5, pp. 1-32, 2011.

[3] M. Byrnes and S. Gerberich, "Motorcycle helmet use and legislation: a systematic review of the literature," Minnesota Medicine, vol. 95, no. 1, pp. 60-65, 2012.

[4] E. Grauwmeijer, M. H. Heijenbrok-Kal, I. K. Haitsma, and G. M. Ribbers, "A prospective study on employment outcome 3 years after moderate to severe traumatic brain injury," Archives of Physical Medicine and Rehabilitation, vol. 93, no. 6, pp. 993999, 2012.

[5] M. P. Alexander, "Mild traumatic brain injury: pathophysiology, natural history, and clinical management," Neurology, vol. 45, no. 7, pp. 1253-1260, 1995.

[6] L. G. Stead, A. N. Bodhit, P. S. Patel et al., "TBI surveillance using the common data elements for traumatic brain injury: a population study," International Journal of Emergency Medicine, vol. 6, no. 1, article 5, 2013.

[7] http://www.cdc.gov/injury/wisqars/ecode_matrix.html.

[8] D. C. Thompson and M. Q. Patterson, "Cycle helmets and the prevention of injuries. Recommendations for competitive sport," Sports Medicine, vol. 25, no. 4, pp. 213-219, 1998.

[9] T. A. Mattei, B. J. Bond, C. R. Goulart, C. A. Sloffer, M. J. Morris, and J. J. Lin, "Performance analysis of the protective effects of bicycle helmets during impact and crush tests in pediatric skull models. Laboratory investigation," Journal of Neurosurgery: Pediatrics, vol. 10, no. 6, pp. 490-497, 2012.

[10] D. C. Thompson, F. P. Rivara, and R. Thompson, "Helmets for preventing head and facial injuries in bicyclists," Cochrane Database of Systematic Reviews, no. 2, Article ID CD001855, 2000.

[11] N. Persaud, E. Coleman, D. Zwolakowski, B. Lauwers, and D. Cass, "Nonuse of bicycle helmets and risk of fatal head injury: a proportional mortality, case-control study," Canadian Medical Association Journal, vol. 184, no. 17, pp. 921-923, 2012.

[12] B. Liu, R. Ivers, R. Norton, S. Blows, and S. K. Lo, "Helmets for preventing injury in motorcycle riders," Cochrane Database of Systematic Reviews, no. 2, Article ID CD004333, 2004.

[13] J. C. Hundley, P. D. Kilgo, P. R. Miller et al., "Non-helmeted motorcyclists: a burden to society? A study using the national 
trauma data bank," Journal of Trauma-Injury, Infection and Critical Care, vol. 57, no. 5, pp. 944-949, 2004.

[14] K. G. Hooten and G. J. A. Murad, "Helmeted versus nonhelmeted: a retrospective review of outcomes from 2-wheeled vehicle accidents at a level 1 trauma center," Clinical Neurosurgery, vol. 59, pp. 126-130, 2012.

[15] M. Miller, D. Davidov, R. Tillotson, C. Whiteman, T. Marshall, and O. Lander, "Injury prevention and recreational all-terrain vehicle use: the impact of helmet use in West Virginia," West Virginia Medical Journal, vol. 108, no. 3, pp. 96-101, 2012.

[16] P. Unni, S. E. Morrow, and B. L. Shultz, "Analysis of pediatric allterrain vehicle trauma data in Middle Tennessee: implications for injury prevention," Journal of Trauma and Acute Care Surgery, vol. 73, no. 4, supplement 3, pp. 277-280, 2012.

[17] T. S. Mueller, "Scooter crashes at university: intervention tactics for modified behavior and helmet use," Traffic Injury Prevention, vol. 14, no. 4, pp. 335-339, 2013.

[18] J. P. Goldstein, "The effect of motorcycle helmet use on the probability of fatality and the severity of head and neck injuries: a latent variable framework," Evaluation Review, vol. 10, no. 3, pp. 355-375, 1986.

[19] S. S. Ooi, S. V. Wong, J. S. Yeap, and R. Umar, "Relationship between cervical spine injury and helmet use in motorcycle road crashes," Asia-Pacific Journal of Public Health, vol. 23, no. 4, pp. 608-619, 2011.

[20] A. Moskal, J. L. Martin, and B. Laumon, "Helmet use and the risk of neck or cervical spine injury among users of motorized two-wheel vehicles," Injury Prevention, vol. 14, no. 4, pp. 238244, 2008.

[21] J. G. Crompton, C. Bone, T. Oyetunji et al., "Motorcycle helmets associated with lower risk of cervical spine injury: debunking the myth," Journal of the American College of Surgeons, vol. 212, no. 3, pp. 295-300, 2011.

[22] F. Servadei, C. Begliomini, E. Gardini, M. Giustini, F. Taggi, and J. Kraus, "Effect of Italy's motorcycle helmet law on traumatic brain injuries," Injury Prevention, vol. 9, no. 3, pp. 257-260, 2003.

[23] D. J. Houston and L. E. Richardson, "Motorcyclist fatality rates and mandatory helmet-use laws," Accident Analysis and Prevention, vol. 40, no. 1, pp. 200-208, 2008.

[24] H. Dao, J. Lee, R. Kermani et al., "Cervical spine injuries and helmet laws: a population-based study," Journal of Trauma and Acute Care Surgery, vol. 72, no. 3, pp. 638-641, 2012.

[25] R. S. Williams, J. Graham, J. C. Helmkamp, R. Dick, T. Thompson, and M. E. Aitken, "A trial of an all-terrain vehicle safety education video in a community-based hunter education program," Journal of Rural Health, vol. 27, no. 3, pp. 255-262, 2011.

[26] J. A. Novak, J. W. Hafner, J. C. Aldag, and M. A. Getz, "Evaluation of a standardized all-terrain safety education intervention for youth in rural central Illinois," Journal of Primary Care and Community Health, vol. 4, no. 1, pp. 8-13, 2013.

[27] P. Rousseau, A. Post, and T. B. Hoshizaki, "A comparison of peak linear and angular headform accelerations using ice hockey helmets," Journal of ASTM International, vol. 6, no. 1, article 11, 2009. 


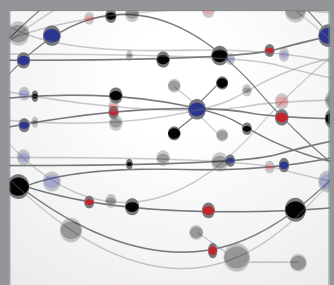

The Scientific World Journal
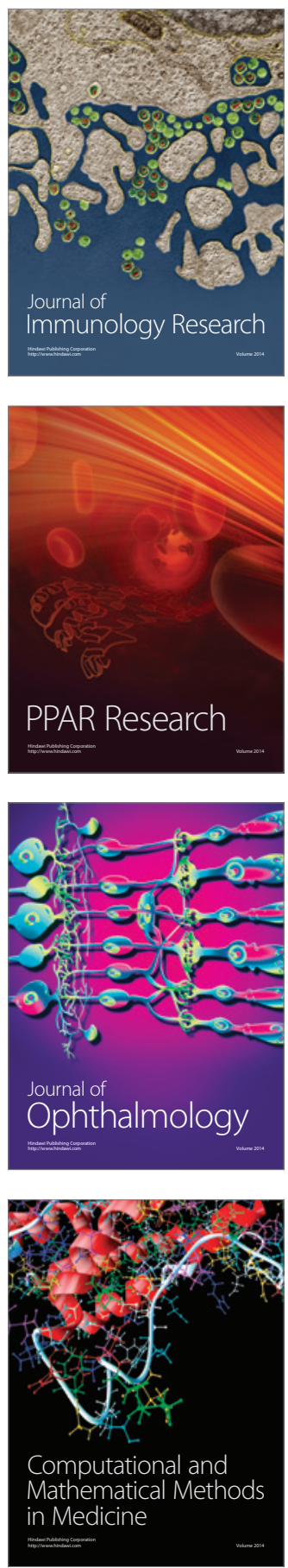

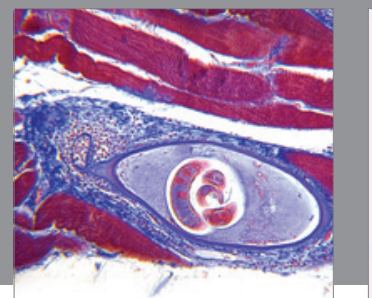

Gastroenterology

Research and Practice
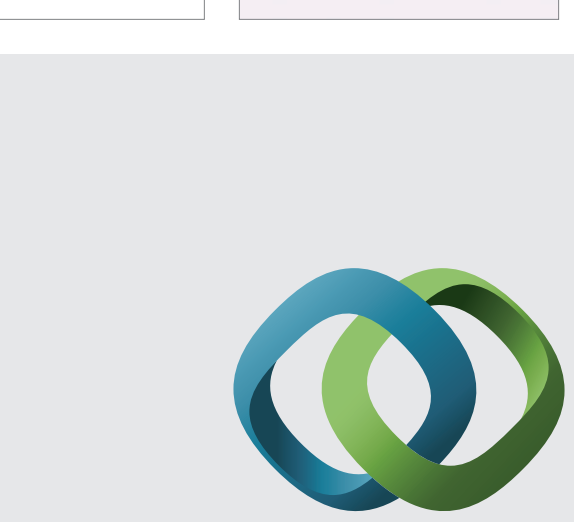

\section{Hindawi}

Submit your manuscripts at

http://www.hindawi.com
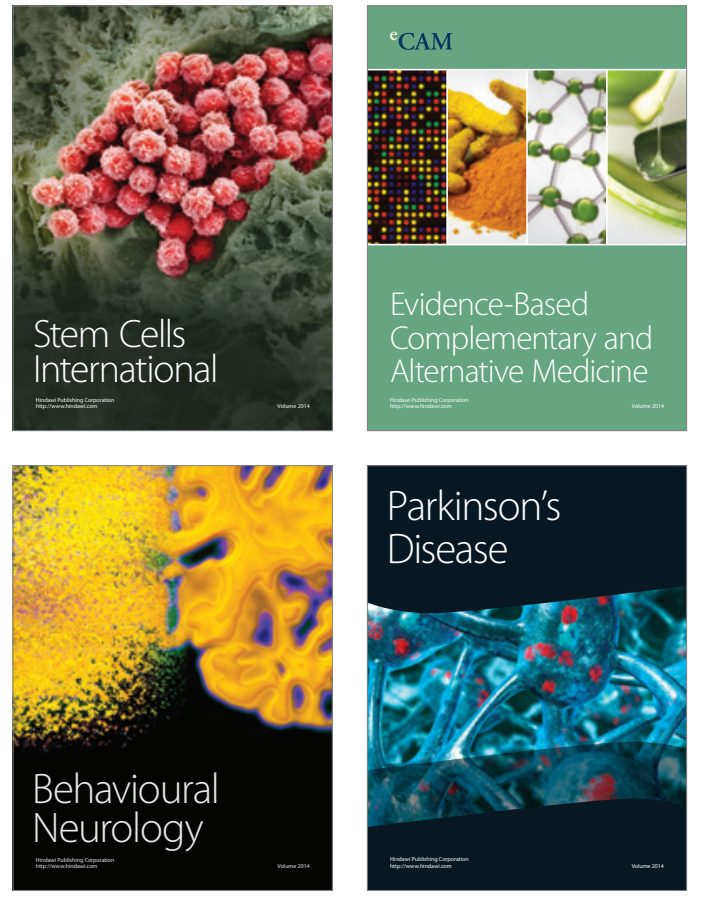
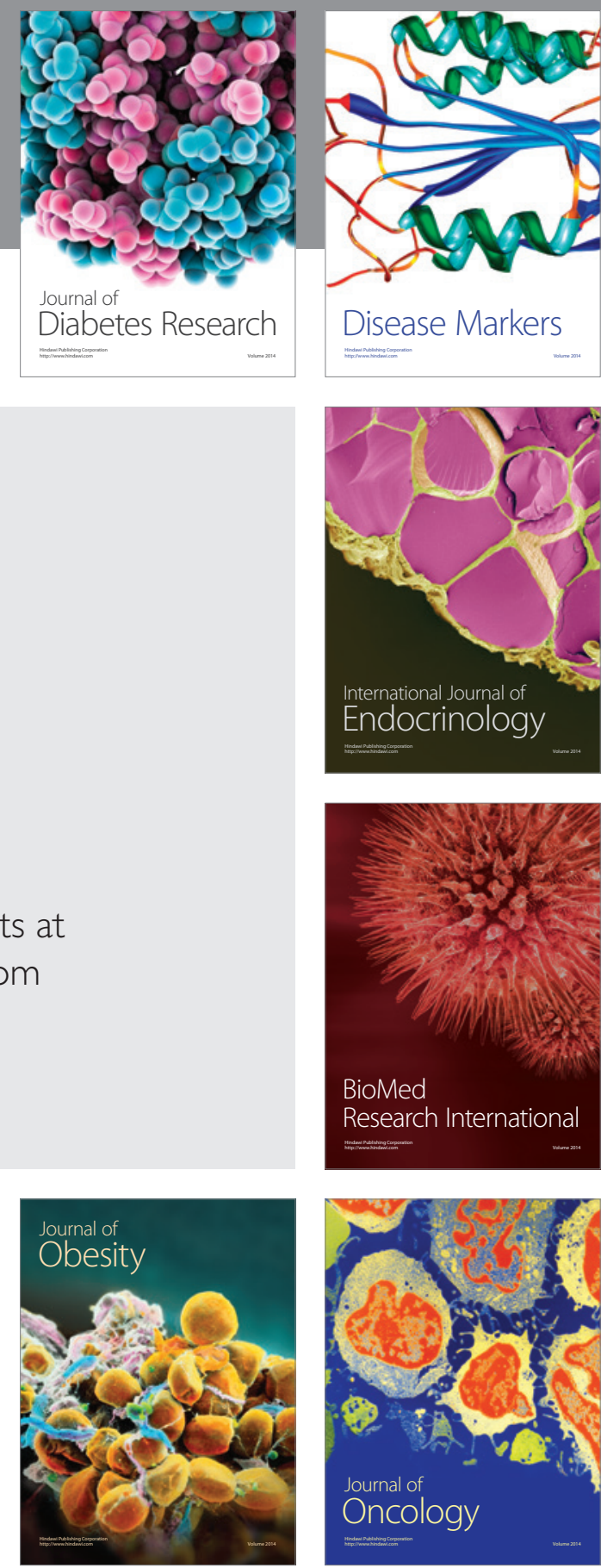

Disease Markers
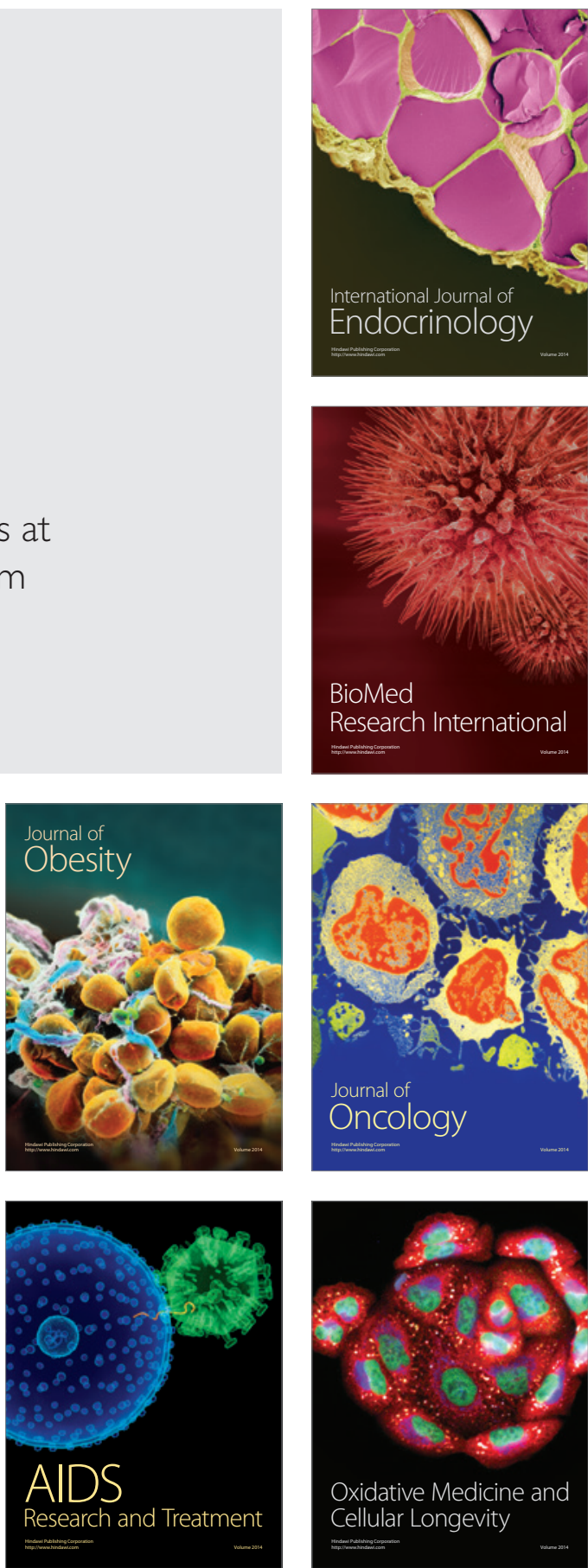